\title{
Multilevel block in the atrioventricular node during atrial tachycardia and flutter alternating with Wenckebach phenomenon
}

\author{
R. Slama, J. F. LeClercQ, M. ROSEngarten, Ph. COUMEL, AND \\ Y. BOUVRAIN
}

From the Clinique Cardiologique, Hôpital Lariboisière, Paris, France

SUMMARY The electrocardiograms of 100 patients with rapid and regular PP intervals during atrial arrhythmias (because of atrial tachycardia or flutter, or pacing) were examined for periods of irregular atrioventricular conduction. This irregular conduction corresponds to an alternating Wenckebach phenomenon, of a type that can be determined from simple rules. The different types of conduction encountered in different patients and the changes seen in the same patient suggest that the atrioventricular node functions physiologically with 3 levels of sequential block. The different prevalence of the 2 types of alternating Wenckebach block may reflect functional differences at the level of the atrioventricular node.

The mechanism of atrioventricular conduction in atrial tachycardia and flutter is unclear. $2: 1$ or $4: 1$ conduction is most commonly seen and these ratios are the easiest to understand. However, conduction is often irregular and among the theories postulated to explain this behaviour is alternating Wenckebach phenomenon (Myerburg et al., 1963; Amat-y-Leon et al., 1975; Guerot et al., 1975; Kosowsky et al., 1976), but little has been published on how to determine the type of conduction from an individual tracing.

We propose a model based on 2 or 3 levels of atrioventricular nodal block, and detail a method to help identify the type of conduction from an individual tracing. Data for the study come from tracings recorded during rapid atrial tachycardia or atrial flutter, or during rapid atrial stimulation continued after reversion of the tachycardia or flutter.

\section{Subjects and methods}

We studied 100 patients with atrial tachycardia or flutter and an absolutely regular PP interval. This was done in the following manner:

(a) The atrial cycle length was measured exactly.

(b) The number of ventricular cycles required to

Received for publication 2 January 1979 make up an exact number of atrial cycles was determined. Starting with a relatively long $R R$ interval, the $R R$ intervals were then added until the total was equal to an exact marked multiple of atrial cycle length, giving a conduction ratio of $x$ ventricular cycles for $n$ atrial cycles.

(c) Special attention was given to changes in the conduction ratio on strips taken from the same patient, especially when the ratio was other than $4: 1$ or $2: 1$.

(d) The tracings were reviewed after treatment with digitalis or amiodarone as these often modified conduction and helped to find the type of block.

(e) Endocavitary studies were performed in the last 20 patients in order to define the level of conduction block.

(f) In those patients whose arrhythmia was successfully treated by atrial stimulation, with restoration to sinus rhythm, the atrioventricular conduction ratio that occurred before conversion was reproduced by incremental atrial pacing.

\section{Results}

TYPE A, ALTERNATING WENCKEBACH PHENOMENON

When the atrioventricular conduction ratio varied between $2: 1$ and $4: 1$ as often seen during drug therapy, the ventricular rhythm was irregular. With conduction ratios of $6: 2,8: 3$, or $10: 4$, the 
PEL
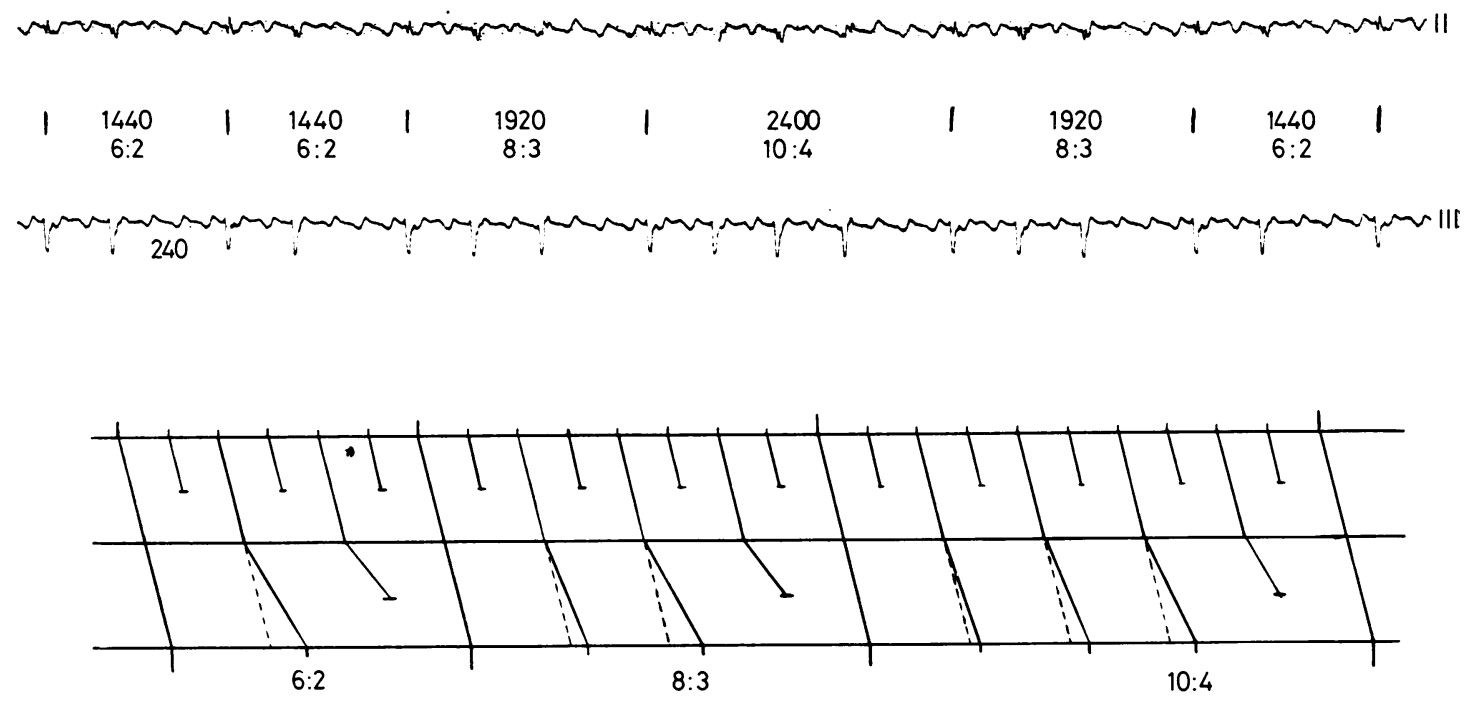

Fig. 1 Type A alternating Wenckebach phenomenon $(\mathrm{x}=\mathrm{n}) /(2-1)$. The number of atrial cycles $(\mathrm{n})$ corresponding to an exact number of ventricular cycles $(x)$ is always even. The variability of the Wenckebach phenomenon in the second zone results in 3 ratios of $\mathbf{n} / \mathbf{x}(6: 2,8: 3,10: 4)$.

stable conduction ratios with variable $R R$ intervals were often modified by periods of varying conduction. This type of conduction can be represented by the following equation:

$$
x=n / 2-1 \text { or } x=\left(\frac{n-2}{2}\right)
$$

This type of conduction is well seen in Fig. 1 and corresponds to type A alternating Wenckebach phenomenon (Kosowsky et al., 1976); it was seen in 75 per cent of our patients. It is due to block at two levels, the first showing 2:1 block, producing $(x=n / 2)$ and the second, the Wenckebach phenomenon, producing $(x=n) /(2-1)$. If this latter Wenckebach phenomenon has a 3:2 ratio, the overall conduction ratio will be $6 / 2$; if the phenomenon has a 4:3 ratio the overall conduction will be $8: 3$. It can be seen that it is easiest to derive this relation by starting from a long $R R$ interval as this corresponds to the impulse blocked in the zone in which the Wenckebach phenomenon occurs.

Sometimes the relation between $x$ and $n$ is not exact because the sum of $x$ ventricular cycles is slightly more than the sum of $n / 2-1$ atrial cycles. The exact relation is seen in the sequence displayed in Fig. 2, where the sum of $x$ ventricular cycles is slightly smaller than expected. This probably represents slowed atrioventricular conduction of the atrial impulse following the Wenckebach period, resulting from concealed conduction of the previously blocked atrial impulse, a phenomenon well known to occur in the atrioventricular node (Langendorf and Pick, 1966). In keeping with this is the finding that the delay seen in the first sequence is exactly compensated by the reduction in the sum of the RR intervals in the subsequent sequence.

\section{TYPE B, ALTERNATING WENCKEBACH} PHENOMENON

Another conduction pattern that may occur (Kosowsky et al., 1976) is usually represented by:

$$
x=\frac{n-1}{2}
$$

In such cases conduction tends to be quite variable and ratios of 5:2, 7:3, and 9:4 may be encountered on the same recording. This model is the inverse of the former and the first level of block is the result of the Wenckebach phenomenon $(n-1)$, with 2:1 block, $x=(n-1) / 2$, at the next level.

Exact 3:1 block is rare and represents alternating Wenckebach phenomenon type B with 3:2 conduction at the second level (Slama et al., 1978). 3:1 conduction is rarely stable and tends to alternate with 5:2 and 7:3 sequences. This second equation only applies to sequences with an odd number of atrial cycles, and applies to half the cases of twolevel block in which the Wenckebach phenomenon 
occurs proximally and 2:1 block distally (Fig. 3). When there is an even number of atrial cycles that encounter this proximal level of Wenckebach block, that impulse conducted after the one that is blocked at the proximal level is, of course, blocked at the distal level. As a result the exact relation between $n$ and $x$ is only seen after two or more Wenckebach periods that is, after the first Wenckebach phenomenon with an even number of atrial impulses, the relation is only seen after a second period of Wenckebach phenomenon comprising an even number of atrial impulses (Fig. 4). As a result, during long recordings, it may be difficult to analyse the relation until one finds a few simple sequences that reveal a type B pattern. This mode of type B conduction can be expressed by the equation:

$$
x=(n-y) / 2
$$

where $x$ is the number of ventricular cycles, $n$ the number of atrial cycles, and $y$ the number of Wenckebach periods.

Rules for atrioventricular conduction during atrial tachycardia or flutter are as follows:

(1) Type A alternating Wenckebach phenomenon implies a conduction ratio of $x=n /(2-1)$.

(2) Type B alternating Wenckebach phenomenon indicates a conduction ratio of $x=(n-1) / 2$.
(3) Type B alternating Wenckebach phenomenon with an even number of atrial cycles, or a type A alternating Wenckebach phenomenon with concealed conduction, can be represented by a conduction ratio of $x=(n-y) / 2$.

The type of alternating Wenckebach phenomenon is usually constant when the patient's condition is stable. Under the influence of various stimuli, however, the type of conduction can change: this may be produced by changes in vagal or sympathetic tone associated with, for example, respiratory variations. Drugs like digitalis have a major effect on atrioventricular conduction and tend to slow it. The usual effect of such drugs is to alter 2:1 conduction to an alternating Wenckebach phenomenon by introducing a second level of block. This usually results in type $A$ alternating Wenckebach phenomenon, though sometimes digitalis transforms type $B$ alternating Wenckebach phenomenon into type A (Fig. 5).

Because $4: 1$ is the maximum conduction ratio with two levels of block, a ratio greater than $4: 1$ implies a third level of block. These 'slow' flutters are found in patients whose atrioventricular nodal function was previously impaired, as might have been seen when they were in sinus rhythm, or after larger doses of drugs like digitalis or amiodarone. In our 8 cases the conduction patterns fits a model
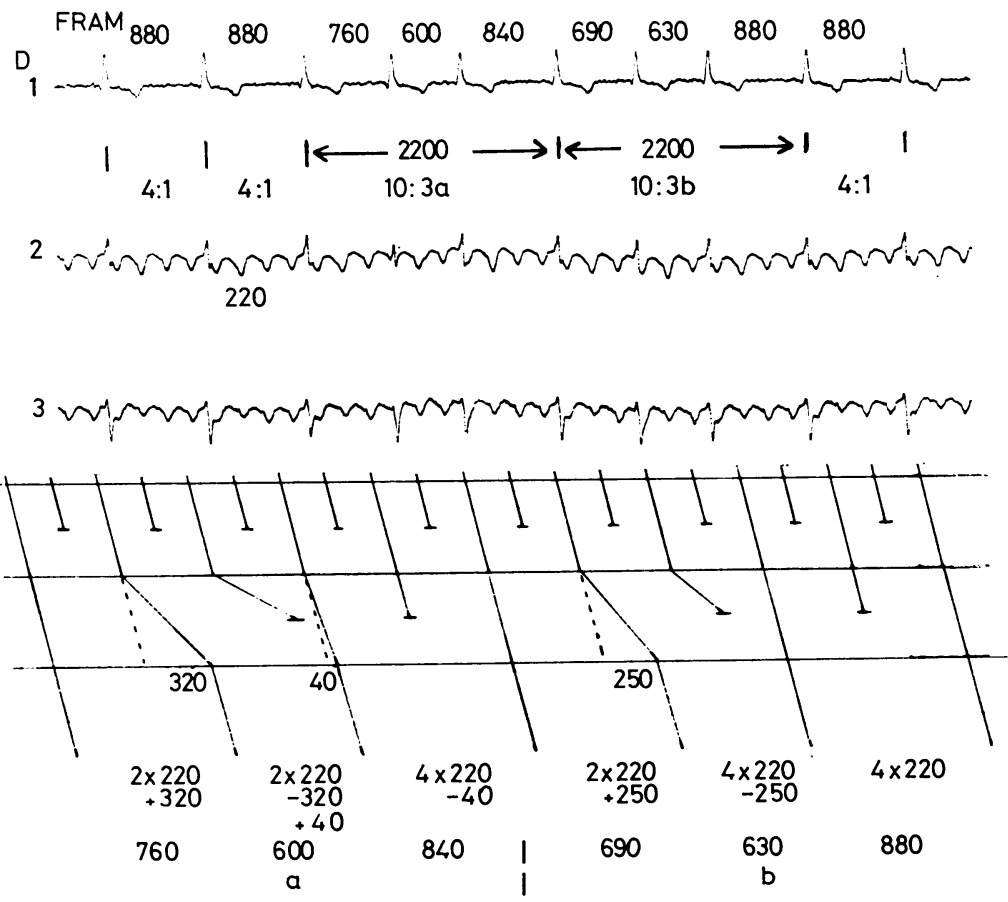

Fig. 2 Type $A$ alternating Wenckebach phenomenon with concealed conduction. During stable $4: 1$ conduction there are $10: 3$ sequences. The last $10: 3$ sequence (b) is divided exactly into $a$ $6: 2$ and $a$ 4:1 sequence. The first $10: 3$ sequence (a) is probably also divided this way, with a concealed atrial conduction between the $6: 2$ and $4: 1$ sequences (diagram). Note that the first $R R$ interval of $760 \mathrm{~ms}$ (a) is longer than that in which it is $690 \mathrm{~ms}$. 


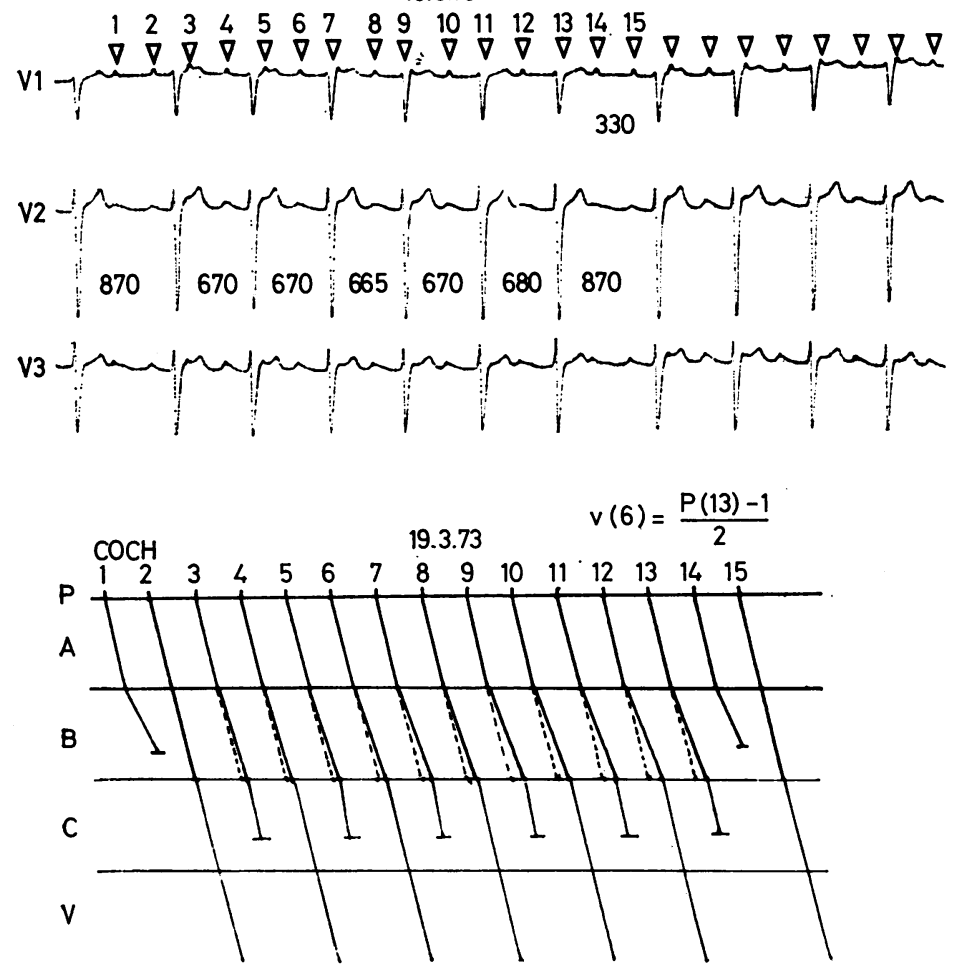

Fig. 3 Type $B$ alternating Wenckebach phenomenon. The conduction ratio of $13: 6$ is explained by a $13: 12$ Wenckebach phenomenon followed by a $2: 1$ block.

VAR

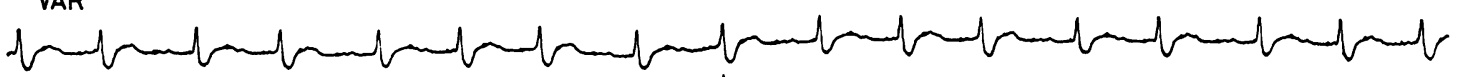

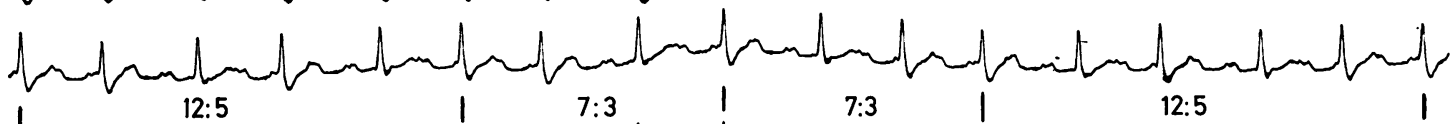
$\begin{array}{llllllll}12: 5 & 1 & 7 & 1 & 1\end{array}$

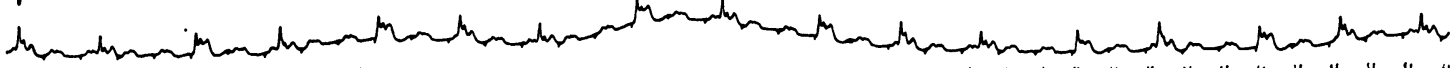

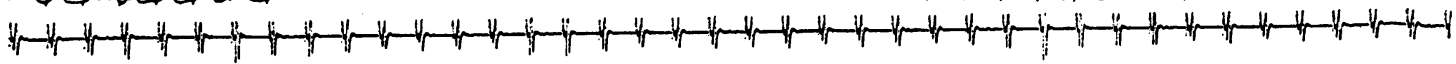

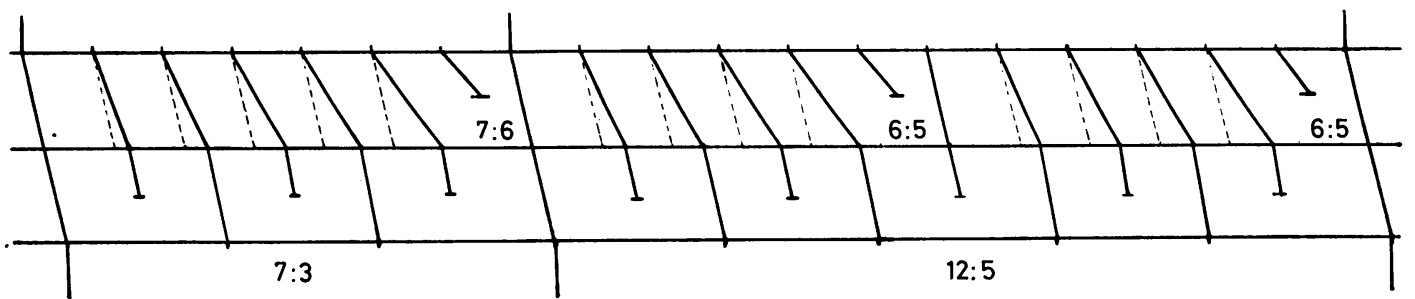

Fig. 4 Type $B$ alternating Wenckebach phenomenon recorded during atrial pacing. The first level of block is $7: 6$ or $6: 5$ Wenckebach phenomenon. A 7:6 Wenckebach phenomenon gives a 7:3 ratio. With a $6: 5$ Wenckebach phenomenon the sixth atrial impulse is blocked by the zone of $2: 1$ block and the following second $6: 5$ Wenckebach phenomenon gives an overall $12: 5$ ratio. 

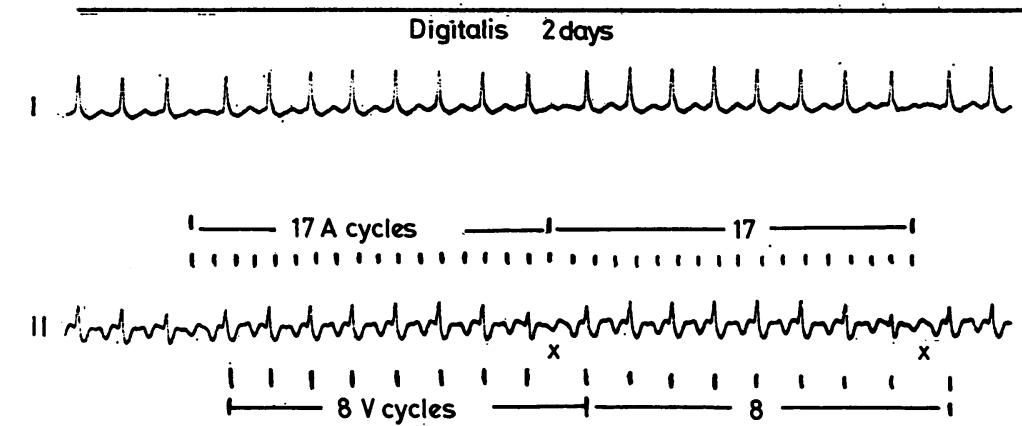

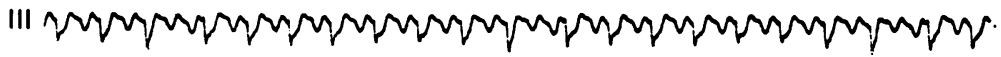

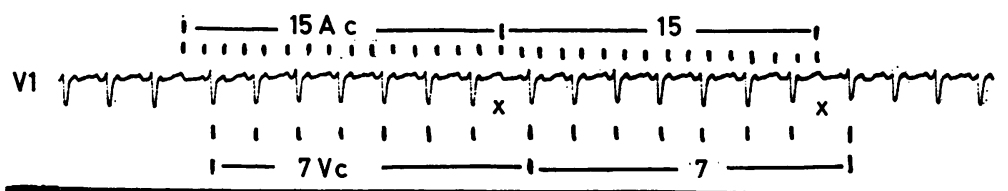

Digitalis 5 days

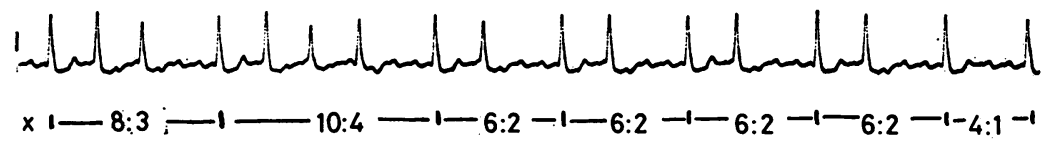

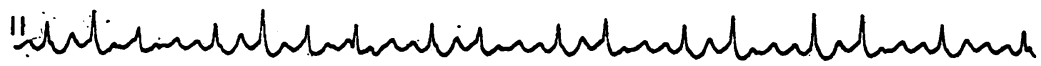

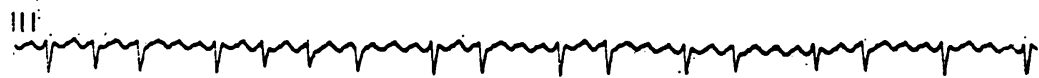

Fig. 5 The effect of digitalis therapy in a case of atrial flutter with 2:1 atrioventricular conduction. After 2 days the conduction becomes a type $B$ alternating Wenckebach phenomenon $(17: 8$ or $15: 7$, where $\mathrm{x}=(\mathrm{n}-1) / 2)$. After 5 days the conduction becomes type $A$ alternating Wenckebach phenomenon $(6: 2,8: 3$, or $10: 4$, where $\mathrm{x}=\mathrm{n} / 2-1)$.

with 2:1 block at the first level, a Wenckebach phenomenon at the second level, and a 2:1 block at the third (Fig. 6).

Our last 20 patients underwent right-sided intracardiac conduction studies. In each case the block was shown to be above the level of the bundle of His, as is usual in atrial flutter (Lau et al., 1969; Dhingra et al., 1973). In 11 cases it was possible to convert them to sinus rhythm by rapid rise atrial stimulation, after which the atrium was then paced at increasing rates. The following sequences of conduction changes were noted: (1) Wenckebach phenomenon; (2) 2:1 block; (3) alternating Wenckebach phenomenon; (4) 4:1 block; (5) block greater than $4: 1$.

If the first alternating Wenckebach phenomenon after 2:1 block was type $A$, this type of conduction was maintained until 4:1 block developed. On the other hand, if it was of type B, a change to type A might be seen before the development of $4: 1$ block (Fig. 7). 

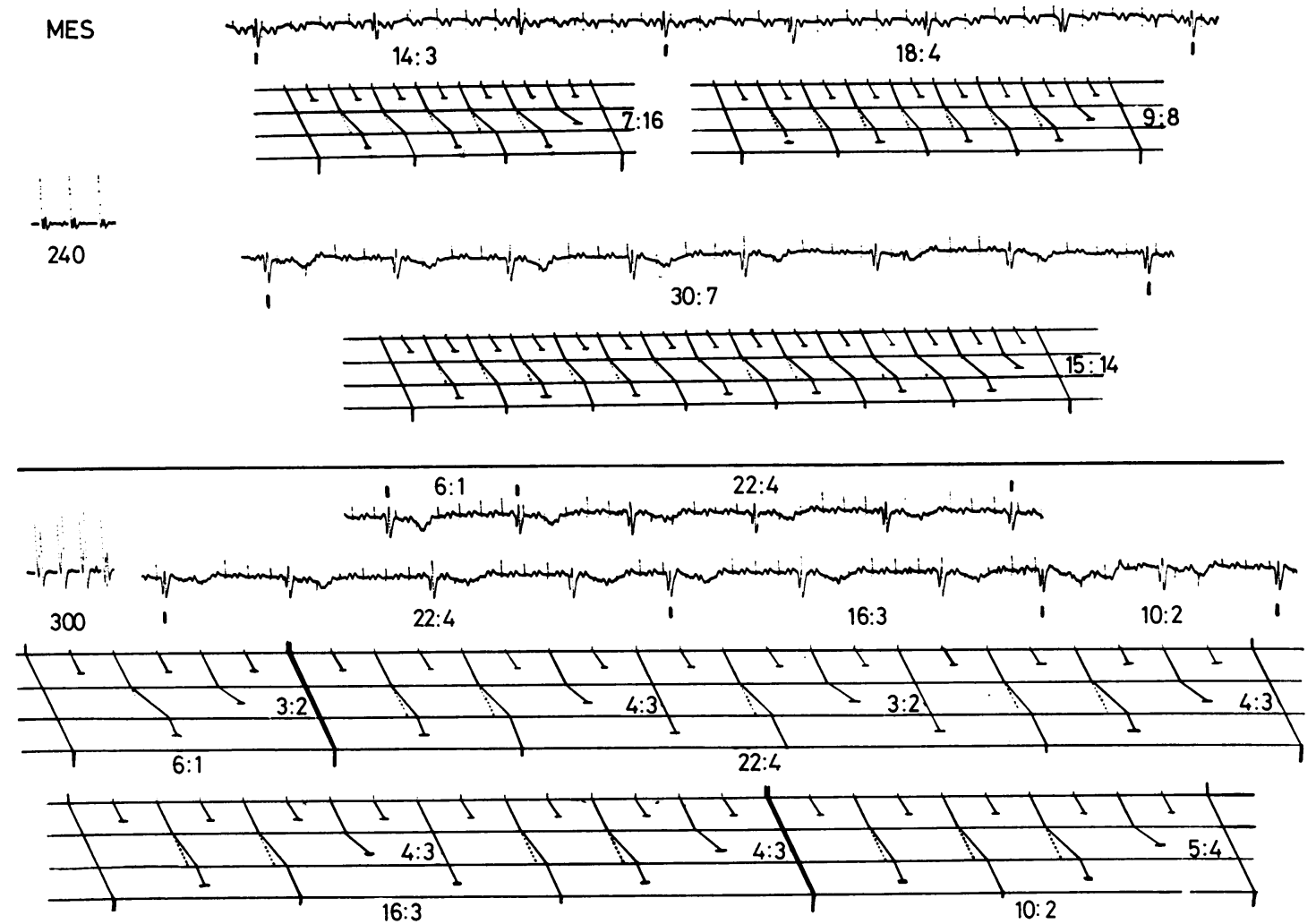

Fig. 6 An example of 3 level atrioventricular block recorded during rapid atrial pacing. The sequence of blocks is always 2:1-Wenckebach phenomenon-2:1. At 240/min there is a low degree of block in the Wenckebach phenomenon zone, that is $7: 6,9: 8$, or $15: 16$, giving $14: 3,18: 4$, and 30:8 sequences. At 300/min the degree of block increases, that is $3: 2,4: 3$, or $5: 4$. When the first Wenckebach phenomenon is $4: 3$, the fourth impulse is blocked below by the $2: 1$ block, and the sequence is completed with a following $4: 3$ sequence.

\section{Discussion}

Our findings of types A and B alternating Wenckebach phenomenon, the fact that they might change from one to the other, and the existence of block of greater degree than $4: 1$ suggest a model of the atrioventricular node with 3 possible levels at which block could occur. When analysis indicates the presence of 2 levels of block, 1 of these 3 levels will conduct in a 1:1 relation. Type $A$ alternating Wenckebach phenomenon is more frequent (Kosowsky, 1976) than the other forms, and corresponds to a block in the first and second levels; type B corresponds to block in the lower 2 levels. Threelevel block, with rare exceptions (Slama et al., 1979), is represented by the model in Fig. 8. Here the first zone (A) shows 2:1 block, the second zone (B) Wenckebach phenomenon, and the third zone (C) 2:1 block.

There are a number of points that conform to this 3-level model of AV nodal conduction with possible block. Electrophysiologists have recognised 3 zones, AN, N, and NH (Mendez and Moe, 1966); the Wenckebach phenomenon is characteristically located in the $\mathrm{N}$ zone. This $\mathrm{N}$ zone corresponds to zone $\mathrm{B}$ of our model, and the $\mathrm{AN}$ and the $\mathrm{NH}$ zones respectively to $A$ and $C ; 3: 1$ conduction has been recognised to occur very rarely (Lewis, 1912), and electrophysiological studies have shown this to be related to conduction disturbance at 2 successive levels (Watanabe and Dreifus, 1967). Further, the higher incidence of type A alternating Wenckebach phenomenon is understandable if one considers the sequence in which the atrial impulses penetrate the atrioventricular node. The impulse rate decreases in the first 2 levels, thus lowering the load on the most distal level and thereby allowing a higher percentage of impulses to be transmitted at that site (type $\mathrm{B}$ alternating Wenckebach phenomenon possibly corresponds to an anomaly in which 

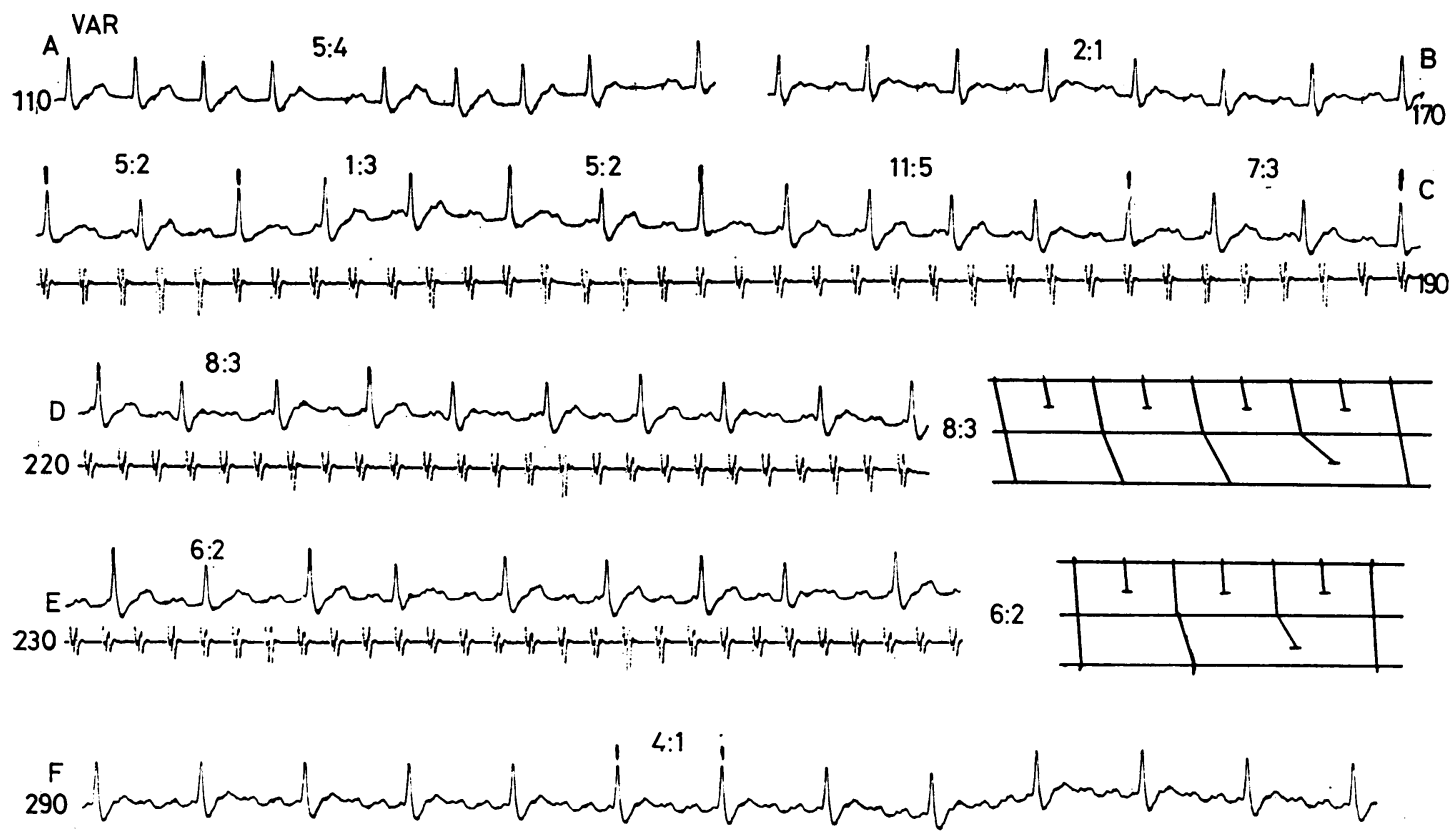

Fig. 7 The atrioventricular response during a progressively increasing atrial pacing rate. (A) Wenckebach phenomenon at 110/min. (B) 2:1 block at 170/min. (C) Type B alternating Wenckebach phenomenon at 190/min. (D) and (E) Type A alternating Wenckebach phenomenon at 220 and 230/min. (F) 4:1 block at 290/min.

there is a short-circuit of the A zone that may represent a condition analogous to the short $P R$ syndrome with either partial bypass of AV nodal fibres or exceptionally good conduction at this zone, with a short refractory period). The alternating Wenckebach phenomenon appears to be a physiological reaction (Amat y Leon et al., 1975; Castellanos et al., 1977; Childers, 1977) and seems to correspond well with the anatomical model.

Finally, though we have seen type B alternating Wenckebach phenomenon converted to type $A$, we have never seen the opposite (an increased block in type A alternating Wenckebach phenomenon proceeds to $4: 1$ conduction without passing through

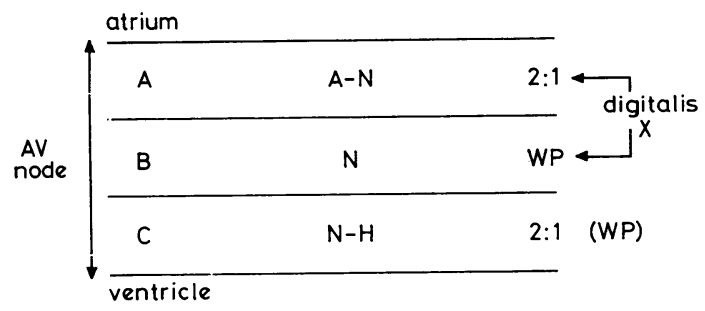

Fig. 8 The model of the atrioventricular node, with 3 possible levels of conduction block. type B block). The change from type B to type A alternating Wenckebach phenomenon implies the development of an additional conduction block in zone $\mathrm{A}$. This reduces the number of impulses that reach zone $C$, and thereby encourages improved conduction in it; this may be analogous to the gap phenomenon. The increased block, whether induced by drugs or pacing, suggests an effect on the proximal part of the atrioventricular node.

We feel that the 3-level model of the AV node that we have proposed explains the majority of cases of alternating Wenckebach phenomenon conduction patterns and that it improves our understanding of the physiology of conduction of the AV node. Based on this model, we suggest simple rules that help determine the type of conduction block.

\footnotetext{
References

Amat-y-Leon, F., Chuquimia, R., Wu, D., Denes, P., Dhingra, R. C., Wyndham, C., and Rosen, K. M. (1975). Alternating Wenckebach periodicity: a common electrophysiologic response. American fournal of Cardiology, 36, 757-764.

Castellanos, A., Sung, R. J., Aldrich, J. L., Mendoza, I. J., and Myerburg, R. J. (1977). Alternating Wenckebach periods occurring in the atria, His-Purkinje system, ventricles and Kent bundle. American fournal of Cardiology, 40, 853-859.
} 
Childers, R. (1977). The AV node: normal and abnormal physiology. Progress in Cardiovascular Diseases, 19, 361-384.

Dhingra, R. C., Rosen, K. M., and Rahimtoola, S. H. (1973). Wenckebach periods with repetitive block: evaluation with His bundle recording. American Heart fournal, 86, 444-448.

Guerot, C., Valere, P. E., and Castillo-Fenoy, A. (1975). Le phénomène de Wenckebach du $2 \mathrm{e}$ degré. Etude clinique et électrocardiographique à propos de 10 cas. Archives des Maladies du Coeur et des Vaisseaux, 68, 1185-1194.

Kosowsky, B. D., Latif, P., and Radoff, A. M. (1976). Multilevel atrioventricular block. Circulation, 54, 914-921.

Langendorf, R., and Pick, A. (1966). Concealed conduction in the A-V junction. In Mechanisms and Therapy of Cardiac Arrhythmias, pp. 395-401, ed. L. S. Dreifus and W. Likoff. Grune and Stratton, New York.

Lau, S. H., Damato, A. N., Berkowitz, W. D., and Patton, R. D. (1969). A study of AV conduction in atrial fibrillation and flutter in man using His bundle recordings. Circulation, 40, 71-78.
Lewis, T. (1912). Auricular flutter. Heart, 4, 171-179.

Mendez, C., and Moe, G. K. (1966). Some characteristics of transmembrane potentials of AV nodal cells during propagation of premature beats. Circulation Research, 19, 993-1010.

Myerburg, R. J., Googman, J. S., and Mariott, J. L. (1963). Atypical forms of the Wenckebach phenomenon. American fournal of Cardiology, 11, 418-423.

Slama, R., Leclercq, J. F., Coumel, Ph., and Bouvrain, Y. (1978). Bloc à deux ou trois étages dans le noeud de Tawara au cours des tachycardies auriculaires. Archives des Maladies $d u$ Coeur et des Vaisseaux, 71, 1322-1340.

Watanabe, Y., and Dreifus, L. S. (1967). Second degree atrioventricular block. Cardiovascular Research, 1, 150-158.

Requests for reprints to Professor R. Slama, Clinique Cardiologique, Hôpital Lariboisière, 2 rue Ambroise-Paré, 75475 Paris Cedex 10, France. 